\title{
Editorial policy: The right to medical information
}

I $\mathrm{n}$ a recent editorial co-published by PLoS Medicine and the Bulletin of the World Health Organization, Barbour and colleagues, ${ }^{1}$ employees of the Public Library of Science (PLoS), make the valid point that "print is no longer the most efficient way to disseminate information." They also argue convincingly that publicly funded researchers have a moral obligation to make the results of their research freely available to everyone. Indeed, the Canadian Institutes of Health Research, ${ }^{2}$ indicating in April 2006 their intention of developing policies that support open-access publication, have invited a number of health researchers to form an advisory committee to consider policies on physical products of research, structural and functional data typically deposited in public databases, as well as peer-reviewed published results. The US National Institutes of Health implemented a similar policy in February 2005, asking that NIH-funded researchers, upon acceptance of their manuscript for publication, voluntarily submit a digital final copy for posting on NIH's PubMed Central. ${ }^{3}$

CMAJ has embraced the policy of open access to its contents on the Internet for nearly a decade and, although it still publishes a print version, its online version is considered the official journal of record. An open-access policy for online content has clear advantages: it makes information available to all who want it regardless of their ability to pay; if necessary, publication can be immediate rather than be delayed in the line-up for print publication; there are no limitations on length; and information is easily accessible. Nevertheless, it also challenges the traditional financial model of the funding of journals through advertising and subscription.

Open-access online journals have proliferated in the past decade. BioMed Central (www.biomedcentral.com) now has more than 150 journals, and the newer PLoS (www .plosjournals.org/perlserv/?request=index-html) has 6 peero reviewed journals. Most open-access journals have a funding model that differs from traditional print journals. Rather than the subscribers and advertisers bearing the cost of editing and production, the authors or their institutions or, indeed, their country, state or province, are expected to cover the cost by means of a publication fee or some other arrangement. Both BioMed Central and PLoS waive publication fees for authors unable to pay (without jeopardy to publication of the manuscript).

Surprisingly few of the major (if impact factor is a measure of importance) international peer-reviewed medical journals have followed $C M A$ \%s example. $B M J$ provides open access to its original research, but JAMA, the New England Journal of Medicine and the Annals of Internal Medicine have bowed to indirect pressure and now provide open access only 6 months after print publication. The Lancet as yet provides no open access. Although most commercial publishers largely follow this traditional funding model, a few commercial publishers are tip-toeing into the open-access, publication-fee model.

Will print journals eventually disappear? Probably not, since we all like the leisure of leafing through our favourite medical journals. But it is clear that busy physicians looking for reliable information on a specific topic will more and more rely on the Internet. Journal publishers and editors will have to explore financial models to secure the viability of Internet and print journal formats, but we adamantly maintain that medical information arising from publicly funded research and from studies involving volunteer subjects in pharmaceutically supported clinical trials must be freely available. The whole purpose of medical research is to provide reliable and valuable health information to the profession and the public. To put that information up for ransom is not acceptable.

\section{Bruce Squires}

Editor Emeritus

CMAJ

Ottawa, Ont.

This article has been peer reviewed.

\section{REFERENCES}

I. Barbour V, Chinnock P, Cohen B, et al. The impact of open access upon public health. Bull WHO 2006;84:337-424. Available: www.who.int/bulletin/volumes 184/5/editorial20506html/en (accessed $2006 \mathrm{Jul} \mathrm{I3}$ ).

2. Canadian Institutes of Health Research (CIHR). CIHR policy in development - access to products of research. Ottawa: CIHR; 2006 Apr 3. Available: www.cihr-irsc .gc.ca/e/30818.html (accessed $2006 \mathrm{Jul}$ I3).

3. NIH calls on scientists to speed public release of research publications [press release]. Bethesda (MD): National Institutes of Health; 2005 Feb 3. Available: www .nih.gov/news/pr/feb2005/od-03.htm (accessed 2006 Jul I8). 